\title{
Molecular basis for interpretation of fulfilled electroretinographic studies
}

\author{
Benn Tonderai-Katsamudanga and Jorge A. Pérez-León* \\ Department of Biological Chemical Sciences, Instituto de Ciencias Biomédicas, Universidad Autónoma de Ciudad Juárez, Ciudad Juárez, \\ Chihuahua, Mexico
}

\begin{abstract}
Fulfilled electroretinography (ffERG) represents the phototransduction process and synaptic network in the first nerve impulse of the visual process. Little is known about its interpretations at molecular level. ffERG records potential changes within the retina in the $a, b$, and $c$ waves coming from different cell types. The a-wave derives from the phototransduction of rods and cones. Depolarization of interneurons is recorded in the b-wave. The origin of the c-wave is controversial. It has been related to the retinal pigmented epithelium, but evidence of its intrinsic electrical activity is lacking. We set the hypothesis that the c-wave measures the activity of the photoreceptor ganglion cells, which results of melanopsin-based phototransduction. The evidence for this comes from experiments inhibiting synaptic transmission from rods and cones. The molecular knowledge is the basis for the interpretation of wave alterations of electroretinographic studies and intrinsically photosensitive retinal ganglion cells contribute substantially to the formation of the c-wave.
\end{abstract}

Key words: Electroretinography. Molecular. Photoreceptors. Phototransduction. Retina. Photoreceptor ganglion cells.

\section{Bases moleculares para interpretar el electrorretinograma}

\section{Resumen}

El electrorretinograma de campo completo (ffERG) es un método no invasivo que representa la fototransducción de los conos y bastones y la transmisión sináptica que genera el impulso nervioso en la vía visual. Se desconocen los procesos moleculares que originan las ondas del ffERG. En la fototransducción de los fotorreceptores, los canales catiónicos activados por nucléotidos cíclicos se cierran y los canales de $K^{+}$permanecen abiertos, hiperpolarizando a estas células, originando la onda a. La onda b proviene de la despolarización de las interneuronas primarias de la retina, principalmente de las células bipolares-ON. A diferencia de estas precisas identificaciones, el origen de la onda c es elusivo, hay propuestas de asociarla con el epitelio pigmentado, aun cuando no hay evidencia de su actividad eléctrica. Este artículo tiene como objetivo analizar resultados publicados que indican que la onda c del ffERG registra la despolarización de las células ganglionares fotorreceptoras (ipRGC), que desarrollan un proceso de fototransducción mediado por la melanopsina. Se revisará evidencia experimental de registros de ffERG bajo la inhibición sináptica intrarretiniana. Los ffERG pueden verse afectados por factores fisiológicos o relacionados con el instrumento, por lo tanto, es necesario determinar la adaptación a la luz y oscuridad, tamaño de la pupila, intensidad del estímulo, tipos de electrodos y selección de fármacos y anestésicos en estudios con animales. Se concluye que la descripción de los mecanismos moleculares forma la base para interpretar las ondas a, b, $c$ d de los ffERG, considerando que las ipRGC contribuyen a la formación de la onda c.

Palabras clave: Electrorretinografía. Interpretación. Base molecular. Fotorreceptores. Fototraducción. Retina.

\section{Correspondence:}

*Jorge A. Pérez-León

E-mail: alberto.perez@uacj.mx
Available online: 17-03-2021

Rev Mex Neuroci. 2021;22(2):56-66 www.revmexneurociencia.com 2604-6180/ @ 2020 Academia Mexicana de Neurología A.C. Published by Permanyer. This is an open access article under the CC BY-NC-ND license (http://creativecommons.org/licenses/by-nc-nd/4.0/). 


\section{Introduction}

Fulfilled electroretinographic (ffERG) studies are non-invasive with a purpose of explaining the levels of functioning of retinal inner cells and they are indicated as pre-operative examinations before cataract surgeries and research into neurodegenerative diseases. Retinal structural changes can be noted before ophthalmic and behavioral signs. Protocols in animals can be short (without anesthesia), revealing mixed responses of rods and cones, while long protocols (with anesthesia) record separate waveforms, coming from the activity of second and third order neurons including that of ganglion cells. In humans, anesthesia is not used. Little is known about electroretinographic (ERG) studies interpretations at the molecular level. Knowledge of how to realize and produce ffERG will help to understand the changes that may be noticed in retinal, neurodegenerative diseases, and toxicological studies ${ }^{1,2}$.

Development of ERG studies began with Gotch Francis in 1903, followed by that of Einthoven and Jolly in 1908. These pioneering investigations resulted in Ragnar Granit explaining an ERG study of a cat in 1933. This resulted in him being awarded the Nobel Prize in $1939^{3}$. ERG studies have since confirmed the hyperpolarization of rods and cones, depolarization of bipolar cells, and controversially concluded that the retinal pigmented epithelium (RPE) is involved in the formation of the $\mathbf{c}$-wave ${ }^{4}$. Other tests like pupillometry are considered to complement its use in determining retinal functioning ${ }^{5}$. As well, retinal toxicity studies during pharmaceutical developments have been confirmed with the use of ERG studies ${ }^{6}$.

The $21^{\text {th }}$ Century has evidenced an increase in molecular biology knowledge. Research in neuro-ophthalmology was not left behind, and a third type of photoreceptor was discovered: the photoreceptor ganglion cell (PRG). This was followed by the elucidation of its phototransduction process which can be recorded and shown on an electroretinogram. ffERG studies can be used to record electrical changes related to the normal functioning of retinal cells and neurodegenerative diseases. Explaining ffERG studies at a molecular level would allow us to diagnose, apply therapies, monitor, and explain different eye diseases with more precision and certainty. There is an increase in the interest of personalized and precision medicine based on scientific- and evidence-based information and various patients can be treated with more certainty using the results obtained from ERG studies. Since the ffERG is the most utilized and most understood in clinical settings, the information provided in this review will be based on its principles. This article will show evidence that the c- wave, which is a depolarization phase after the $\mathbf{b}$ wave, is related to the phototransduction process of PRGs.

\section{Methods}

A literature search during the period of December 2018 and December 2019 was done and information was obtained from the databases of PubMed, Google Scholar, and Elsevier. The following keywords were used during the searches: electroretinography, interpretation, molecular basis, photoreceptors, phototransduction, and retina. Most of the articles considered were published after the year 2000, with few exceptions. A total of 300 articles were considered to have relevant information and those included in this review were having updated information about the molecular basis for the interpretation of ERG studies. Criteria used to select the articles were based on the author's contributions to the area of research and experience.

\section{Phototransduction process in rods and cones}

ERG studies are graphical representations of the phototransduction process in the retina (Figs. 1 and 2, Table 1). The phototransduction in the classical photoreceptors, cones, and rods, initiates the process of the vision. When a photon interacts with conopsin and rhodopsin the isomerization of retinaldehyde from 11-cis to trans activates the $G$ protein, transducin. The transducing alpha subunit -GTP complex activates the phosphodiesterase (PDE), which cleaves cyclic GMP (cGMP), to 5 '-GMP. The reduction in cGMP leads to cyclic nucleotide gated channels closure. Thus, rods and cones light response is the hyperpolarization and in the dark, depolarization of these photoreceptors occurs ${ }^{7-11}$.

In the hyperpolarized photoreceptors, voltage gated $\mathrm{Ca}^{2+}$ channels also close and thus the $\mathrm{Ca}^{2+}$ mediated vesicle release of glutamate is suppressed. Because the occurrence of the distinct glutamate receptors on retinal neurons, the decrease in the amount of glutamate released by the photoreceptors causes the depolarization of the ON bipolar cells and the hyperpolarization of the OFF bipolar cells ${ }^{11,12}$. 
Table 1. Comparison of phototransduction processes within retina

\begin{tabular}{l|l|l|l|}
\hline Photoreceptor cell type & Rod & Cone & Photoreceptor ganglion cell \\
\hline Pigment & Rhodopsin & Conopsin & Melanopsin \\
\hline G protein & Gtransducin & Gtransducin & Galpha q \\
\hline intracellular mechanism & $\begin{array}{l}\text { Phosphodiesterase activation, } \\
\text { cGMP hydrolysis, CNG cationic } \\
\text { channel closure }\end{array}$ & $\begin{array}{l}\text { Phosphodiesterase activation, } \\
\text { cGMP hydrolysis, cationic } \\
\text { channel closure }\end{array}$ & $\begin{array}{l}\text { Phospholipase activation, IP3/DAG } \\
\text { synthesis, opening TRP cationic } \\
\text { channel }\end{array}$ \\
\hline Cell response & hyperpolarization & hyperpolarization & depolarization
\end{tabular}

cGMP: cyclic guanosine monophosphate; CNG: cyclic nucleotides gated channel; IP3, inositol triphosphate; DAG: diacylglycerol; TRP: transient receptor potential channel.

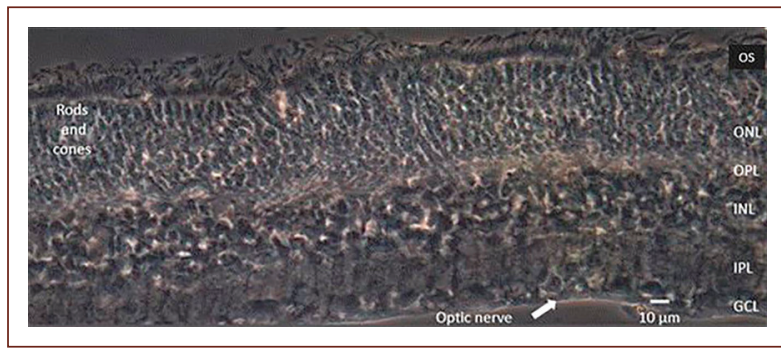

Figure 1. Vertical section of the rabbit retina showing the histological layers. photoreceptor outer segments (OS); Photoreceptor cells somata in the outer nuclear layer $(\mathrm{ONL})$; the plexus for synapses between photoreceptor cells and interneurons in the outer plexiform layer (OPL); the interneurons somata (inner nuclear layer, INL); synaptic plexus of interneurons and ganglion cells (inner plexiform layer, IPL) and ganglion cell layer (GCL). Cryostat sectioning and phase contrast microscopy, image from the authors.

\section{Phototransduction process in intrinsically photosensitive retinal ganglion cells (ipRGC)}

The phototransduction process is not exclusive of rods and cones. An exceptional group of ganglion cells contains melanopsin, a homolog of conopsin, and rhodopsin. Melanopsin- activates a signal cascade that opens a cationic channel in the plasma membrane of these ganglion cells, which, thus, are intrinsically photosensitive and hence known as PRG cells. They convey the environmental illuminance information, to the suprachiasmatic nuclei by the retinohypothalamic tract $(\mathrm{RHT})$ and play a key role in the photosynchronization of the circadian cycle ${ }^{13}$.

The phototransduction process of ipRGCs (Fig. 3, Table 1) is homolog to that started by opsins in classical photoreceptors, melanopsin also uses 11-cis-retinaldhyde as chromophore. However, melanopsin activates a heterotrimeric $\mathrm{G}$ protein of the $\mathrm{Gq} / 11$ family, and results in the depolarization of the ipRGCs. The $\mathrm{Gq} / 11$ alpha subunit activates phospholipase $C \beta$ and the hydrolysis of phosphatidylinositol-4,5-bisphosphate $\left(\mathrm{PIP}_{2}\right)$. PIP $\mathrm{P}_{2}$ hydrolysis produces the second messenger's diacylglycerol (DAG) and inositol 1,4,5 triphosphate $\left(\mathrm{IP}_{3}\right)^{14,15}$. It is supposed that DAG opens a canonical TRP channel activating a cationic current which depolarizes the PRG as it occurs in Drosophila photoreceptors. The depolarization-induced by the light in ipRGCs exceeds the trigger threshold, generating $\mathrm{Na}^{+}$action potentials, which are required for these cells to signal through their long axons to higher encephalic targets.

Like other opsins, melanopsin consists of an apoprotein covalently linked 11-cis-retinal chromophore. The absorption of a photon isomerizes the chromophore in all-trans-retinal. After exposure to light, the trans-retinal in a photopigment must be re-isomerized to 11-cis-retinal to make the pigment photo excitable again. For the rods, isomerization depends on the retinal pigmented epithelium, while the cones depend on the Müller glia. In contrast, photo-activated melanopsin retains all-trans-retinal and isomerize to 11-cis-retinal after exposure to light, in a process known as photo-reversion. Apart from being a photopigment, melanopsin also has the ability to reisomerize the all-trans-retinal back to 11-cis-retinal. This capability is known as "photoisomerase activity", and it occurs also in the opsins of some invertebrate species ${ }^{16}$.

Besides the phototransduction process described above, PRG are third order neurons which receive synaptic inputs from bipolar and amacrine cells temporal and spatial summation of these synaptic inputs can also lead to triggering of action potentials of the PRG which solely form the RHT. Therefore, it can be concluded that PRG have a synaptic and an intrinsic component (the 


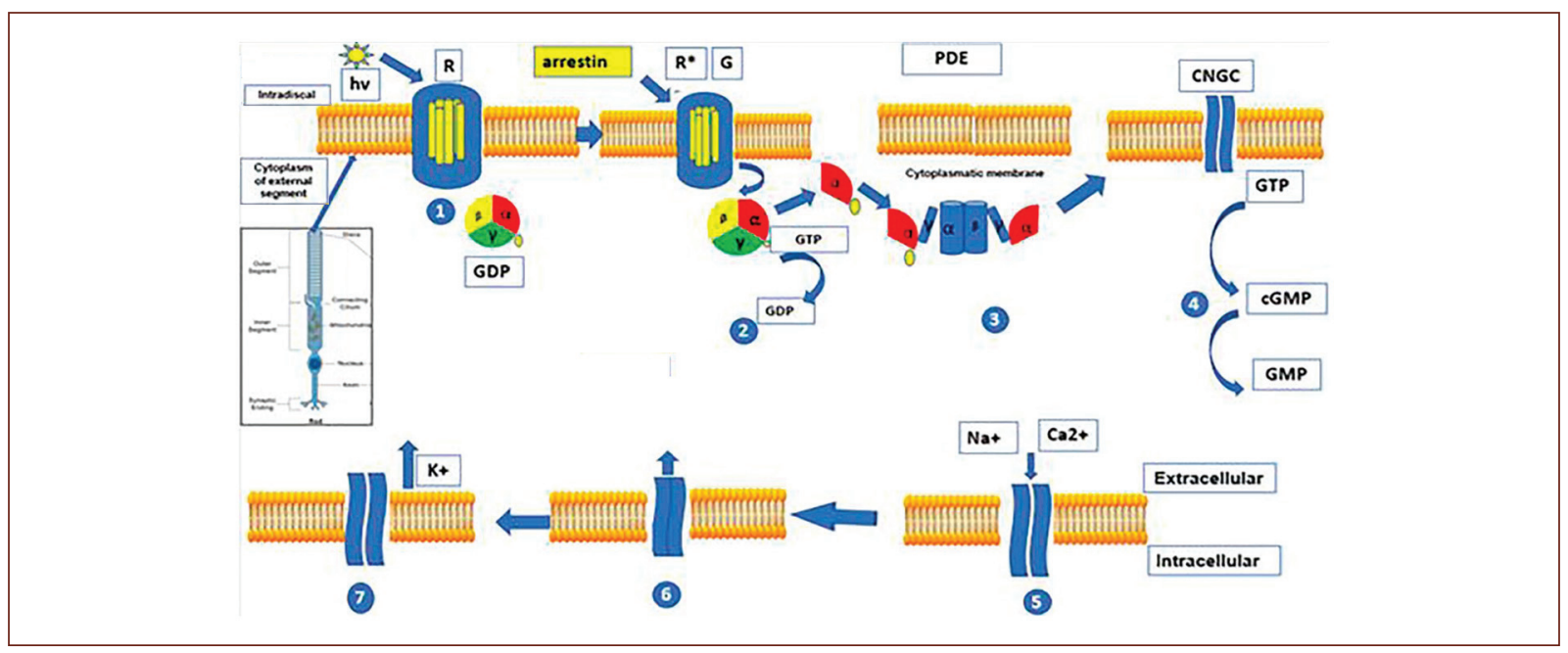

Figure 2. Phototransduction process in the outer segment of rods and cones. Light causes the isomerization of retinal and rhodopsin/conopsin. This leads to the activation of $G$ protein transducin. The transducin alpha subunit activates the enzyme phosphodiesterase and thus the hydrolysis of cyclic guanosine monophosphate. This leads to the closing of cyclic nucleotide-gated channels. This reduces the inward current of $\mathrm{Na}^{+}$and $\mathrm{Ca}^{2+}$ and coupled with the continued outflow of $\mathrm{K}^{+}$through the $\mathrm{Ca}^{2+} / \mathrm{K}^{+} / \mathrm{Na}^{+}$ion exchanger, this will lead to the hyperpolarization of photoreceptors. Arrestin will bind activated rhodopsin/conopsin and will cause desensitization of this process (adapted from Milosavljevic, et al. 2016$)^{70}$.

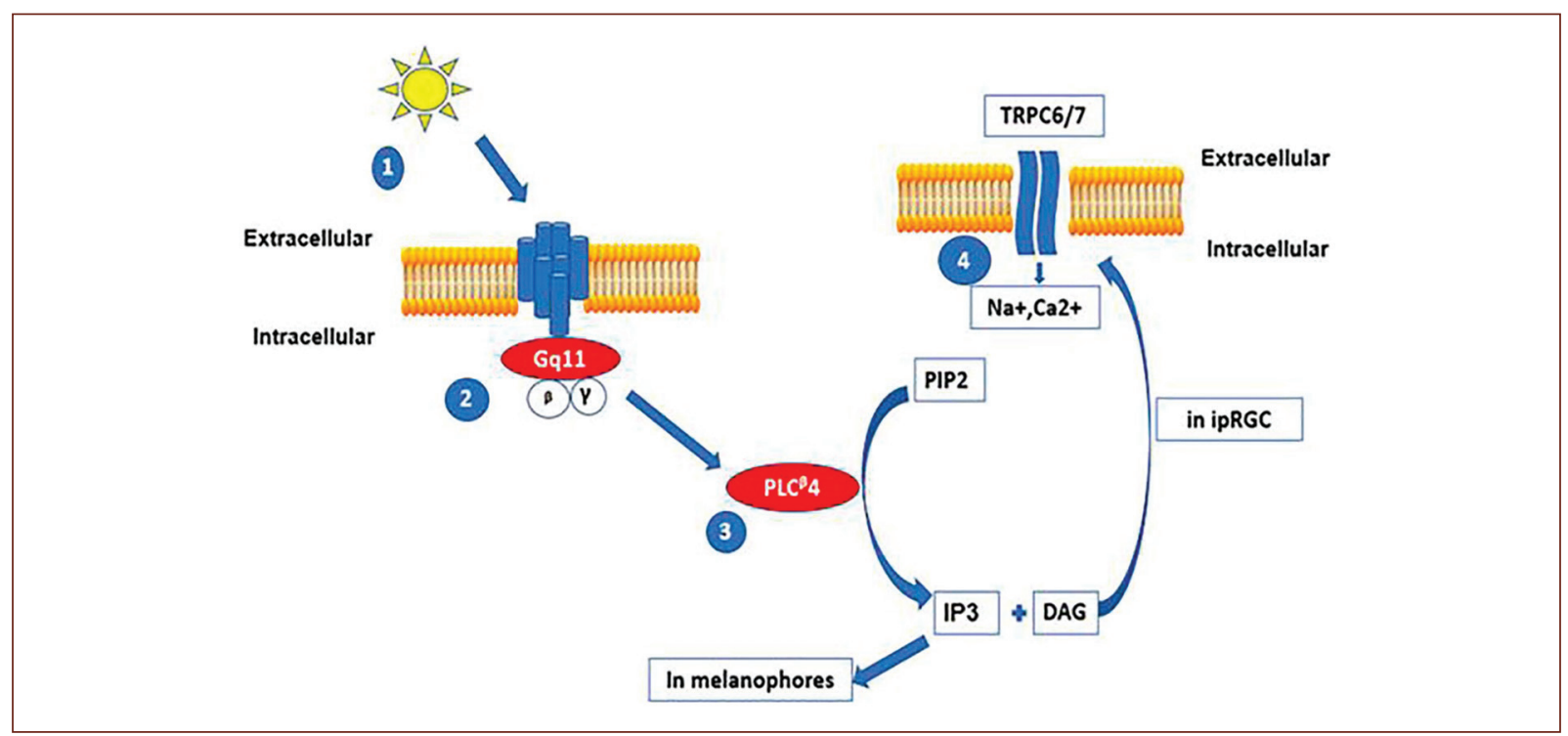

Figure 3. Phototransduction process in intrinsic photosensitive retinal ganglion cells (ipRGCs). Light induces the isomerization of retinal and melanopsin. This leads to the activation of a family of Gaq protein coupled to phospholipase $C$ enzymes. The hydrolysis of phosphatidyl-inositol $\left(\mathrm{PIP}_{2}\right)$ to form inositol-triphosphate $\left(\mathrm{IP}_{3}\right)$ and diacyl-glycerol (DAG) will activate different intracellular transduction mechanisms in melanophores, IP3 will open $\mathrm{Ca}^{++}$channels in endoplasmic reticulum. In ipRGCs, DAG will promote the opening of plasma membrane transient receptor potential channels TRPC and the inward current of $\mathrm{Na}^{+}$and $\mathrm{Ca}^{2+}$ ions. The ipRGCs response is a depolarization of membrane voltage ladapted from Hughes, et al., 2012) ${ }^{71}$.

phototransduction process of melanopsin) which are reflected in their response recorded, altogether with that from the others regular ganglion cells, in the ffERG c- wave ${ }^{17}$. 


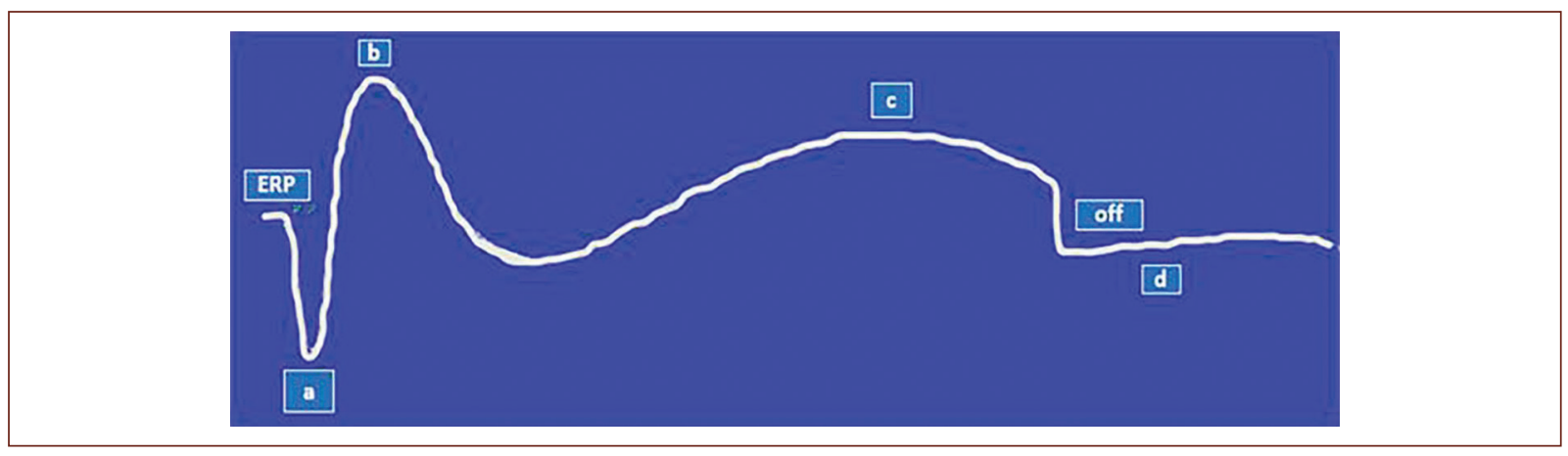

Figure 4. Schematic graphic representation of full-field electroretinogram (ffERG) study showing several types of voltage changes from different retinal cell neurons. These voltage traces are known as ERG waves. The early receptor potential (ERP) is the field potential of retinal photoreceptors in a resting phase. The a-wave, hyperpolarization is related to the phototransduction process of rods and cones while the b-wave, a depolarization, is related to changes in the potential of bipolar cells. The c-wave, depolarization, is being hypothesized to be related with PRG while the off portion marks the end stage of the record of ERG. The $\mathbf{d}$-wave is the intermittent part between generations of two complete ERG studies (adapted from Creel, 2020)72.

\section{ffERG studies}

ffERG studies are useful tools for assessing retinal cells in vivo ${ }^{18}$ and changes in the form of the waves can be related to the distinct types of cells involved in an electroretinogram. The changes in membrane potential of the photoreceptors can be large enough to be detected by probes on the corneal surface and reference positions. In a ffERG, the recordings are average potential changes of retinal cells which result in an ERG study (Fig. 4) where there is a measurement of the amplitude of $a, b, c$, and d waves in microvolts $(\mu \mathrm{V})$ and latency/implicit time in milliseconds ${ }^{3}$.

The ffERG study is the standard for retinal electrophysiological studies while the multifocal electroretinography (mfERG) analyses specific regions of the retina at a specific moment ${ }^{19}$. A ffERG study will allow having a global analysis of retinal function ${ }^{20}$. Other retinal electrophysiological studies include ERG pattern which analyses electrical changes in the macular ganglion cells while an electrooculogram helps to analyze the RPE. Visual evoked potentials are a measurement of the electrical signals recorded at the scalp over the occipital cortex in response to light stimulus and detect changes in electrical transmission in the optic nerve and post- retinal pathways ${ }^{21}$ while a $\mathrm{mfERG}$ measures specific region of the retina.

The recording of ffERG studies is composed of three stages, mainly: acquisition, fitting and amplification, and signal processing ${ }^{3}$. The duration of light that causes electrical changes captured in ffERG studies has a range of $50-100 \mathrm{~ms}^{22}$. During a ffERG study, there is variation in intensity, wavelength, and duration of stimuli. A rod driven response is recorded with a stimulus of 0.01-0.02 cd.s. $\mathrm{m}^{-2}$ in dark-adapted conditions, while increasing to $3 \mathrm{~cd} . \mathrm{s} . \mathrm{m}^{-2}$ would stimulate cones and result in a mixed rod-cone response. By increasing to $30 \mathrm{~cd} . \mathrm{s} . \mathrm{m}^{-2}$ would result in a pure cone response in photopic conditions. Using a flickering stimulus of $31 \mathrm{~Hz}$ would, as well, result in a pure cone response ${ }^{23}$.

To make a technically viable study, calibration of the stimuli and of the ffERG machine is necessary. This would have negative effects on the measurements of latency and amplitudes of the waves. Inconsistent calibration may result in misleading data ${ }^{24}$. As a way of preventing accommodation of the retinal photoreceptors, the times between light stimuli should be regulated. Stimuli of up to $0.01 \mathrm{~cd} . \mathrm{s} . \mathrm{m}^{-2}$ should be separated by $2 \mathrm{~s}$; up to 0.1 cd.s. $\mathrm{m}^{-2}$ should be by $3 \mathrm{~s}$ while those of up to $3 \mathrm{~cd} . \mathrm{s} . \mathrm{m}^{-2}$ should be separated by $5 \mathrm{~s}$. For higher intensities, they should be separated by at least $10 \mathrm{~s}^{25}$. As well, measurements in an ffERG are susceptible to electrode drift, eyeball, and eyelid movements and for this reason sedatives are proposed to be used in animal studies ${ }^{26}$.

In scotopic conditions, the b waves predominate the capture of the results ${ }^{27}$. Examples of ffERG recordings have demonstrated that $\mathrm{b}$ waves are smaller in amplitudes of young rabbits but without variation in implicit times ${ }^{28}$. The first part of an ERG study is a small electrical activation of the receptors and it is found near or on the baseline. It is known as an early receptor potential, ERP. The hyperpolarization of rods and cones spans the first $15 \mathrm{~ms}$ of the a- wave ${ }^{29}$. The b- wave is due to the depolarization of inner retinal neurons predominantly ON-bipolar cells. While the c- wave has 
Table 2. Cell and molecular correlates for waves recorded in a ffERG

\begin{tabular}{|l|l|l|l|}
\hline ffERG wave & a-wave & b-wave & c-wave \\
\hline $\begin{array}{l}\text { Fluctuation from baseline } \\
\text { voltage }\end{array}$ & Hyperpolarization & Depolarization & Depolarization \\
\hline Cell type involved & Rods and cones & $\begin{array}{l}\text { Inner retinal neurons mostly } \\
\text { ON bipolar cells }\end{array}$ & Photoreceptor ganglion cells \\
\hline Molecular events & $\begin{array}{l}\text { Closure of CNG by rod/cone- } \\
\text { opsin phototransduction }\end{array}$ & $\begin{array}{l}\text { Inhibition of metabotropic } \\
\text { glutamate receptors }\end{array}$ & $\begin{array}{l}\text { Activation of TRP channels by } \\
\text { melanopsin phototransduction* }\end{array}$ \\
\hline
\end{tabular}

*Mechanism proposed based on evidence showed in this review. ffERG: full-field electroretinogram; CNG: cyclic nucleotides gated channel; TRP: transient receptor potential channel. Baseline voltage refers to the field potential recorded right before light stimulation.

been related to the RPE, but the authors show evidence below that it is rather related to ipRGCs.

In one study, intravitreal injections of 6-hydroxydopamine, a degenerating agent for dopamine neurons, in rabbits' eyes, the depletion of dopamine increased the amplitude of the $\mathbf{b}$ - wave. This was related to the suppression of lateral inhibition by dopaminergic amacrine cells which in the intact retina modulate synaptic transmission between the inner synaptic and inner nuclear layers in the retina ${ }^{29-31}$.

The ratio of b-wave to a-wave amplitude is used to denote the normal transmission of the electrical signal of the retina. Any change will be reflected in this ratio ${ }^{22}$.

The c- wave has always been confused with oscillatory potentials and a knowledge of how they originate can help to know when there is a dysfunction in the process of phototransduction. The early, intermediate, and late peaks are generated mainly by photoreceptors, action potential- independent, and action potential-dependent interactions on third-order cells on the ON pathway. Bipolar, horizontal, and neurons on the OFF pathway make a small contribution to the generation of these waves ${ }^{31}$. The oscillatory waves appear on the rising phase of the $b$ waves and using the bandpass filter they can be isolated of the ERG for their analysis. They are known as well as oscillatory potentials and they are thought to arise from inner plexiform layer ${ }^{22}$.

Earlier studies have suggested that the $\mathbf{c}$ - wave originated from the pigmented epithelium RPE, reviewed by Perlman ${ }^{22}$. For instance, one study which was done after the dissection of the RPE from the retinal components resulted in the disappearance of the $\mathbf{c}$-wave and in amphibians the c- wave could be recorded after the transection of optic nerve, which leads to degeneration of retinal ganglion cells. The mechanism proposed to the origin of c- wave by RPE is based on the fact that its apical pole (facing the retinal layers) is more permeable to $\mathrm{K}^{+}$ions than the basal pole (facing the choroid) which leads to a transepithelial potential. The changes in extracellular $\mathrm{K}^{+}$following the response of rods and cones increase the transepithelial potential with the retinal face more positive, reflected as the generation of the $c$ - wave in the ERG. Thus, even though the c- wave originated from RPE still depends on the rods and cones phototransduction mechanism. Aside that, the analysis of the $c$ wave can tells about the integrity of the classical photoreceptors ${ }^{22}$.

At the present, there is no sufficient evidence that the c-wave is exclusively contributed by the PRG. The only reports that have been put forward have been about the chemo genetic activation of PRG, a manipulation which drives changes in dark-adapted electroretinograms. There are also data from a mouse retina ex vivo study, in which rods and cones ablation did not prevent the appearance of $c$ wave, which was produced in response to a light stimulus on the range of activation of melanopsin.

Therefore, it can be hypothesized that PRG contribute to the formation of the $c$ waves. The authors propose that inhibition of the synaptic transmission by glutamate metabotropic and ionotropic receptors ligands and transient receptor potential canonical (TRPC) 6/7 channels can demonstrate the intrinsic properties and contribution of ipRGC to the c- wave.

An understating of retinal circuits can help to understand the processes that may be involved in the production of a ffERG (Table 2). In scotopic conditions, rod bipolar cells synapse with amacrine cells and the signal are then transmitted through the cone bipolar to ganglion cells ${ }^{32}$. The main neurotransmitter in the retina is L-glutamate and the use of agonists and antagonists can help to determine the contribution of each rod and cone pathways on the ffERG. Injection of APB and blockage of the central retinal artery caused the disappearance of the $\mathbf{b}$ waves. APB acts on the 


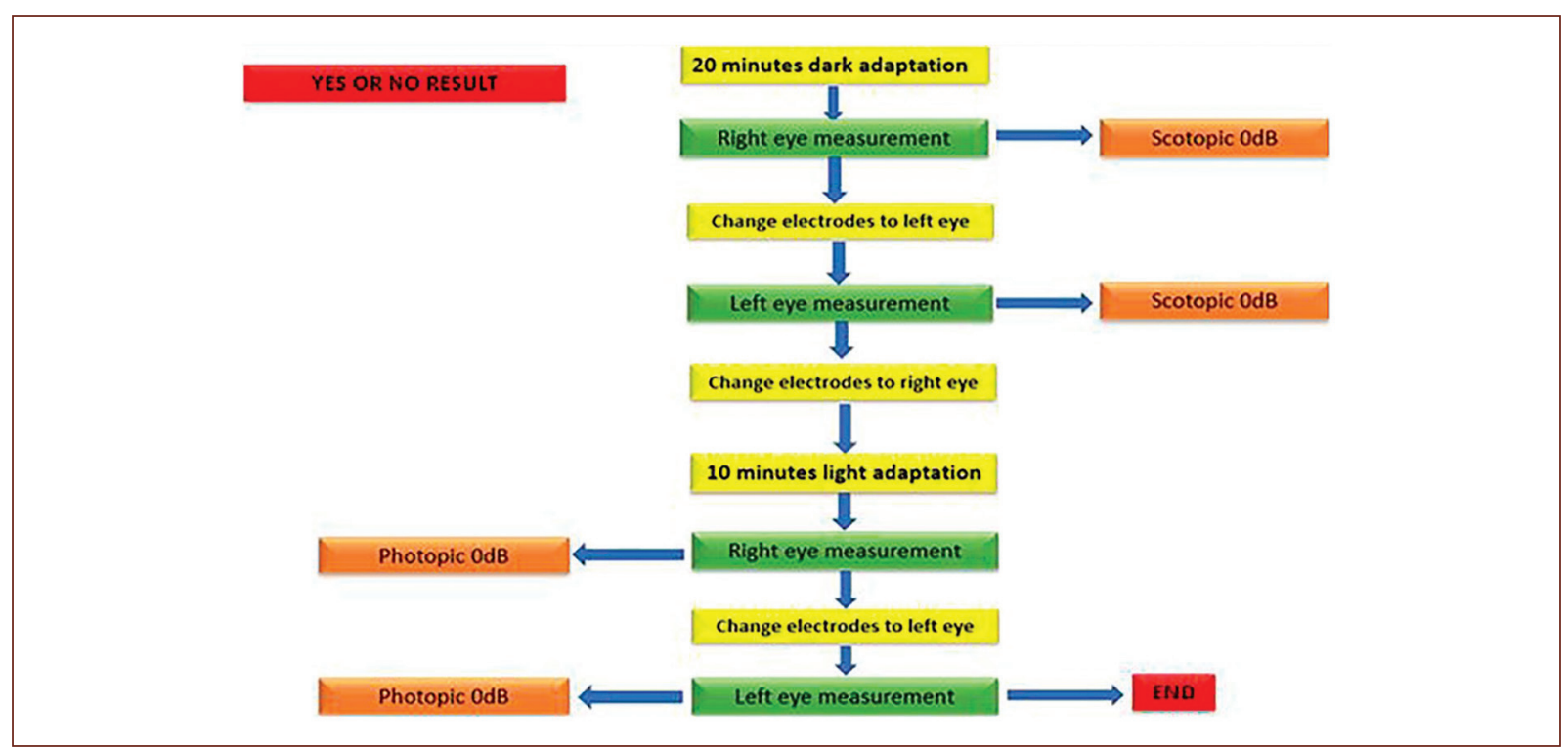

Figure 5. Short protocol for ERG studies with a standard flash of $3 \mathrm{cdsm}^{-2}$. Yellow=steps to take; Green=measurement stages; Orange=Light intensities. The procedure begins with a 20-min dark adaptation period, followed by the placement of electrodes on the right eye and measurement at $0 \mathrm{~dB}$. Then, the electrodes will be changed to the left side, which will then be followed by placement of corneal electrodes on the same side and measurement at $0 \mathrm{~dB}$. The experimental subjects are then light adapted for 10 min with measurements being done at right and left sides at $0 \mathrm{~dB}$. The result will be yes or no under scotopic and photopic conditions.

metabotropic receptors inhibiting the bipolar cells ON pathway while DNQX, an inhibitor of AMPA/KA glutamate type receptors, eliminates pathways that block the formation of $\mathbf{b}$ waves, enhances the appearance of the $\mathbf{b}$ waves. Tetrodotoxin would slightly reduce and would delay time to peak for $\mathbf{b}$ waves while the combination of bicuculline and strychnine would increase $i^{22}$. Knowledge of the retinal circuits involved in the process of transmission of the light signals raises some questions on how the pigmented epithelial cells can form part of these pathways and how they can lead to the formation of the $\mathbf{c}$ waves. By retrograde labeling using alpha herpes pseudorabies virus and immunofluorescence studies, it was determined that PRG are transinaptically connected to the bipolar, amacrine, and dopaminergic cells which form part of the retinal circuits. For these reasons, the authors are putting forward the hypothesis that the PRG are the source of the formation of $\mathbf{c}$ waves.

\section{Strategies of evaluation of ERG studies and protocols}

The way in which a ffERG study is done is based on established protocols which generally can be defined as short and long. There is no use of anesthesia during the short protocol and it is mostly applied in humans. The result is a yes or no on the function of the retina. A variation of light intensity would result in variation of amplitudes of the a, b, and c waves (Figs. 5 and 6). On the other hand, the long protocol based on the European College of Veterinary Ophthalmologists guidelines includes the use of anesthesia, and is generally applied for research purposes in animals.

\section{Factors affecting ERG studies}

Factors affecting full-filled ERG studies can be divided into physiological or instrument-related and the results are a summation of the changes in potentials of the individual photoreceptors ${ }^{1}$. The amplitudes recorded on a ffERG study depend on the animal's eye condition, the light adaptation of the eye, the intensity of the stimulus, pupil size, and electrodes condition ${ }^{33}$. Eyeball movements were shown to cause changes in ffERG measurements due to changes in electrode-corneal contact and intensity of incident light. As a way of minimizing these effects, it was demonstrated that a mixture of ketamine and xylazine had the best results in rats. Minimum eye movement along with maximum level of $\mathbf{a}$ and $\mathbf{b}$ wave 


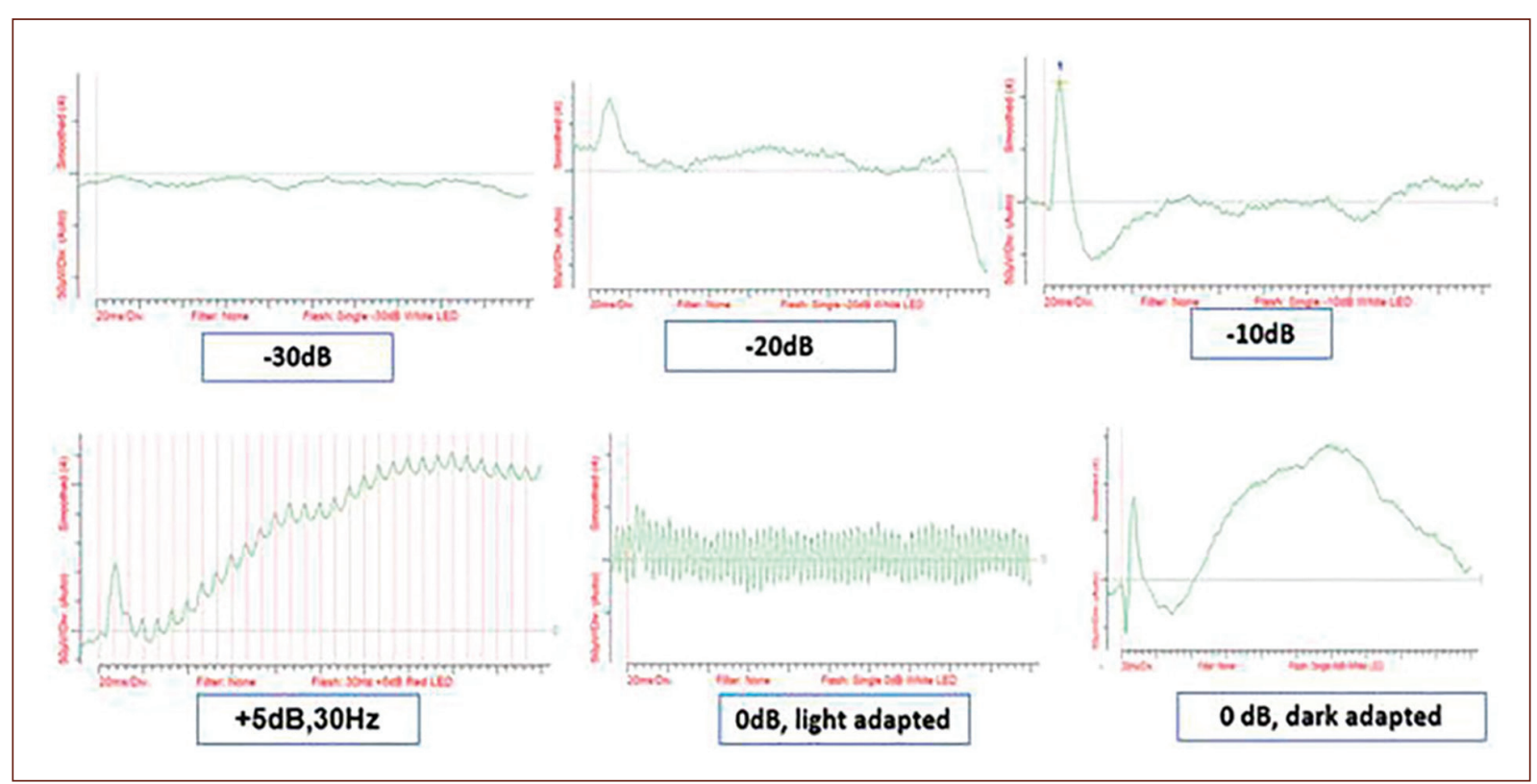

Figure 6. Example of a ffERG obtained applying the short protocol showing ERGs at different light intensities after scotopic and light adaptation. Every plot shows the changes in amplitudes ( $Y$ axis, microvolts) during recording time (X axis, milliseconds) at increasing light intensity. Subject, New Zealand rabbit, 2 months old. Results from an ongoing study of the authors.

amplitudes were recorded. There was insignificant variation in implicit times with this combination as well ${ }^{34}$.

The ffERG is influenced by dark/light adaptation time, pupil size, stimulus intensity, electrodes, alertness level, and other factors ${ }^{35}$. The use of skin-electrodes produces lower amplitudes of $a$ and $b$ waves and longer implicit times when compared with corneal ones, making it a better option when doing ffERG studies ${ }^{36}$. Bipolar corneal electrodes have a high signal-noise ratio thus causing repetition of studies with longer periods and fewer stimulus elements necessary for the results to be comparable. The major cause for poor records would be related with electrode skin and corneal contact ${ }^{29}$.

The results from recent studies have shown that there is variation between in vivo and ex vivo studies. In an in vivo dark-adapted study, the b- wave dominated and was four-fold in amplitude and time to peak was $60 \mathrm{~ms}$ when compared with a wave that had time to peak of $30 \mathrm{~ms}^{22}$. While in an ex vivo studies are slower and have suppression of oscillatory potentials when compared with in vivo studies ${ }^{37}$.

In a study using white New Zealand rabbits with a weight of between 2-2.5 kg and 8-10 weeks old, it was determined that the test-retest reliability was based on the levels of variability of the investigation. The largest variability, $30 \%$, was between the subjects, followed by
$20 \%$ between the repetitions and $10 \%$ between the eyes $^{38}$. On measurement of the effects of different drugs on the $\mathbf{c}$ waves, it was demonstrated that there was no statistical difference in results of the left and right eyes of the same animal; therefore, the contralateral eye should always be used as a control ${ }^{39}$. A three-fold increase in pupil size equaled a nine-fold increase in light intensity reaching the retina. Therefore, pupil dilation can affect ERG studies. Another factor studied was the level of brightness of the stimulus. The brighter the stimulus the faster the ffERG and reduced time to peak levels ${ }^{22}$.

\section{Effects of anesthesia on ffERG studies}

Since some protocols of ffERG studies are done under anesthesia, there is a great need to know their effects. Diazepam and barbiturates at high doses cause a decrease of the a-wave while the combination of xylazine and ketamine has been shown to have fewer effects on ffERG studies'. There were no significant differences in the amplitudes and implicit times of $a$ and $b$ waves in a study in cats when the combination of ketamine-xylazine and dexmedetomidine-ketamine was compared ${ }^{40}$. Propofol would cause an increase in b- wave amplitude while dexmedetomidine would have a decrease in $\mathbf{b}$ waves compared to the 
tiletamine-zolazepam combination. Isoflurane would cause further decreases in all waves when combined with the others mentioned before ${ }^{41}$.

When used intravenously at a dose of $1-2 \mathrm{mg} / \mathrm{kg}$, ketamine cataleptic effect lasted $<1 \mathrm{~min}$ while at a dose of $5-10 \mathrm{mg} / \mathrm{kg}$ it took 20-40 min. These factors should be considered when conducting the study of ffERG. Halothane and thiopental would cause an increase in implicit time of waves $a$ and $b$ waves ${ }^{42}$. Lidocaine and bupivacaine are normally used as local anesthetics for retrobulbar injections and with the use of ffERG studies, it was demonstrated that they are non-toxic ${ }^{43}$. Initial studies on the effects of anesthesia on ffERG waves demonstrated that $1.3 \%$ vol of halothane increased the amplitudes of the $b$ waves while during the same experiments artificial ventilation did not cause any changes ${ }^{44}$.

\section{Ocular and retinal diseases and their effects on ffERG studies}

ffERG studies reveal the state of function of retinal cells $^{3}$ and in mammals it establishes the loss of vision related to retinal degeneration diseases which can be divided into primary (hereditary) and secondary (glaucoma-related). For example, infectious inflammatory diseases like canine distemper can cause retinal detachment ${ }^{45}$. Retinal detachment and attachment surgeries have also used ffERG studies as a diagnostic tool wherein one study they obtained a decrease in amplitude of $\mathbf{b}$ waves after detachment and an increase in implicit time ${ }^{46}$.

Glaucoma is a heterogeneous group of disorders related to retinal cell apoptosis, specific optic neuropathy, and cupping of the optic disc. Although an increase in intraocular pressure has been linked to an increase in the risk of development of glaucoma, some authors argue that there is a presentation of glaucoma in humans with normal intraocular pressure. In such a situation other non-invasive tools for determining normal visual processes like ERG studies would be of beneficial use $\mathrm{e}^{47,48}$. It is a result of interaction between genes, age, and environmental factors ${ }^{49}$.

The following genes have been determined in various canine species to be related to the development of open-angle glaucoma: ADAMTS10, ADAMTS17 COL1A2, RAB22A, NEB, and SRBD ${ }^{50}$ as well as LTBP2 and TGF beta $^{51}$. Its alluded that neuroinflammation is the key process during glaucoma. The retinal ganglion cells are the first to be affected followed by astrocytes and microglia. Microglia responds with a phagocytic process to restore homeostasis and these results in monocyte infiltration ${ }^{52}$.
Retinal ganglion cell death is a result of apoptosis whereas cells that continue to live have the protection of neurotrophins ${ }^{53}$.

Axonal degeneration models have demonstrated that autophagic flux impairment results from elevated intraocular pressure, TNF, traumatic injury, ischemia, oxidative stress, and aging ${ }^{54}$. Age-related trabecular meshwork changes have been linked to the activation of myofibroblasts which leads to the reduction of the iridocorneal angle. In primary open-angle glaucoma, there is a loss of endothelial cells due to the action of oxidants like hydrogen peroxide causing apoptosis and mitochondrial damage in the trabecular meshwork ${ }^{55}$. As well, long-term use of glucocorticoids has been related to iatrogenic open-angle glaucoma ${ }^{56}$. Possible contributors to the development of glaucoma are neurotrophins signaling, oxidative stress, excitotoxicity, mitochondrial dysfunction, protein misfolding, hypoxia, and retinal ischemia ${ }^{57}$.

On increasing intraocular pressure in a rabbit, which is common in glaucoma, and equalizing it with the arterial blood pressure the c-wave disappeared first and then the a-wave after $1 \frac{1}{2} \min$ and the $b$ - wave will disappear ${ }^{58}$. Since normal standard visual field tests cannot detect initial changes related to glaucoma, it was demonstrated that there was a decrease in amplitude and increase in latency of the N2 wave of the middle area of the retina using a mfERG ${ }^{59}$. The diameter of the retina was between 100 and $200 \mu \mathrm{m}$. In general, in acute retinal degeneration diseases the amplitudes of $a$ and $b$ waves decrease, while implicit time is prolonged when studies are done in scotopic conditions. In chronic situations, the same changes are noticed after both scotopic and photopic adaptation ${ }^{3}$.

In diabetic retinopathy loss of vision has been related to the elevation of vascular endothelial growth factor (VEGF), and retinal central vein occlusions as well as neovascularization of the anterior chamber has been linked to elevated VEGF in the aqueous humor. The inhibition of the proliferation of VEGF would help to analyze its effects that can be reflected in an ffERG study. Intravitreal local injection of Bevacizumab, with no systemic effects, did not show any effects on the amplitudes of $a$ and $b$ waves making it a better option in the treatment of age-related macular degeneration and diabetic retinopathy ${ }^{60}$. In diabetic retinopathy, there is inadequate glycemic control which is related to a weakening of small blood vessels which can lead to the formation of microaneurysms, bleeding, edema, and ischemia of retinal cells. In the end, this will result in neovascularization and retinal detachment ${ }^{61}$. 
One of the retinal diseases that have been demonstrated to influence the ffERG studies is retinitis pigmentosa, which is a genetic defect and the degeneration of the classic photoreceptors, rods and cones, and retinal ganglion cells ${ }^{62}$.

Long- term administration of antiepileptic drugs like vigabatrin, a gamma-aminobutyric acid (GABA) analog and inhibitor of GABA aminotransferase have been linked to vision loss due to its effects on bipolar cells which contribute to the formation of $b$ waves and do express GABA receptors ${ }^{63,64}$. Blockage of the GABA feedback system attenuates significantly the $\mathbf{b}$ waves and confirmed that it is an important pathway for the formation of $b$ waves.

Using a multifocal type of ERG (mfERG), cataracts of distinct levels of opacity cause a reduction in amplitude of $a$ and $b$ waves ${ }^{65}$. In a flicker ffERG, cataracts reduce the intensity and scatter light on the retina. Thus, it stimulates a larger area and in contrast, increases the amplitude of ERG on the peripheral area when compared to the macular area ${ }^{66}$. Although these changes might have been noticed, they did not find any statistical differences before and after cataract surgeries and concluded that ffERG is a dependable pre-surgical ocular examination ${ }^{67}$.

Age has been noted as a crucial factor during ERG studies. With the use of albino rabbits, it was noted that a wave appears during the first 2 weeks while the band oscillatory wave appears after that. The b-wave reaches its maximum amplitude at 40 days and this result justifies ERG studies to be done after 6 weeks ${ }^{68}$. During the development of the retina, the ganglion cells are the first to differentiate then followed by neurons of the outer retina, sequentially amacrine, classical photoreceptors, and bipolar cells. Thus, photoreceptors' responses in the recently born individual are less than those that have a matured visual system ${ }^{69}$. Having all the information presented thus creates a need to know the molecular basis for ERG studies.

\section{Conclusions}

It was concluded that molecular-based knowledge forms the basis for the interpretation of $a, b$, and $c$ wave changes of ffERG studies and ipRGCs have a contribution to the formation of the c-wave.

\section{Acknowledgements}

The following people provided so much support and comments while this paper was being revised: Carolina
Montelongo Ponce, Alejandro Botello Camacho, Marisela Aguirre Ramírez, Roxana Malpica Calderón, Gustavo Adolfo García Sánchez, and Julián Lozano Pérez.

\section{Financing}

Benn Tonderai-Katsamudanga is a fellow of Consejo Nacional de Ciencia y Tecnología (CONACyT). Work in Pérez-León lab is supported by: Programa integral de Fortalecimiento Institucional (PIFI) 2007-2008, 2909 5001-004-09. PROMEP Apoyo a Cuerpos Académicos 2013. Programa para el Fortalecimiento de la Calidad de las Instituciones Educativas, 2015 (PROFOCIE). Reconocimiento al Perfil Deseable PRODEP-SEP 2019.

\section{Conflicts of interest}

None.

\section{Ethical disclosures}

Protection of human and animal subjects. The authors declare that no experiments were performed on humans or animals for this study.

Confidentiality of data. The authors declare that no patient data appear in this article.

Right to privacy and informed consent. The authors declare that no patient data appear in this article.

\section{References}

1. Balicka A, Trbolová A, Vrbovská T. Electroretinography (a review). Folia Vet. 2016;60:53-8.

2. Kelawala DN, Deepak P. Electroretinography (ERG) for clinical evaluation of vision abnormalities a clinical study of 9 dogs. Intas Polivet. 2016;17:429-31.

3. Quintana ML, Benedetto MM, Maldonado AC, Vera de Payer E, Contin MA. Electroretinography: a biopotential to assess the function/ dysfunction of the retina. J Phys. 2016;705:012053.

4. Ishikawa H. Pupil and melanopsin photoreception. Nippon Ganka Gakkai Zasshi. 2013;117:246-68.

5. Huang W, Collette W $3^{\text {rd }}$, Twamley M, Aguirre SA, Sacaan A. Application of electroretinography (ERG) in early drug development for assessing retinal toxicity in rats. Toxicol Appl Pharmacol. 2015;289:525-33.

6. Whiting RB, Yao G, Narfström K, Pearce JW, Coates JR, Dodam JR, et al. Quantitative assessment of the canine pupillary light reflex. Invest Ophthalmol Vis Sci. 2013;54:5432-40.

7. Laha B, Stafford BK, Huberman AD. Regenerating optic pathways from the eye to the brain. Science. 2017;356:1031-4.

8. Fitzackerly J. Phototransduction. Minnesota: University of Minnesota Medical School. Available from: https://www.d.umn.edu/ jfitzake/Lectures/ UndergradPharmacy/SensoryPhysiology/Vision/Phototransduction.html.

9. Kim IJ, Zhang Y, Yamagata M, Meister M, Sanes JR. Phototransduction and visual processing in retina. Molecular identification of a retinal cell type that responds to upward motion. Nature. 2008;452:478-82.

10. Augustine PD. Phototransduction. In: Purves D, Augustine GJ, Fitzpatrick D, Katz LC, LaMantia AS, editors. Neuroscience. $2^{\text {nd }}$ ed, Sundererland, MA: Sinauer Associates; 2001. 
11. Leskov IB, Klenchin VA, Handy JW, Whitlock GG, Govardovskii VI, Bownd $M D$, et al. The gain of rod phototransduction: reconciliation of biochemical and electrophysiological measurements. Neuron. 2000;27:525-37.

12. Physiology Plus. The Process of Phototransduction. Available from: http:// www.physiologyplus.com/describe-the-process-of-phototransduction.

13. Do MT, Yau KW. Intrinsically photosensitive retinal ganglion cells. Physiol Rev. 2010:90:1547-81.

14. Chew KS, Schmidt TM, Rupp AC, Kofuji P, Trimarchi JM. Loss of Gq/11 genes does not abolish melanopsin phototransduction. PLoS One. 2014:9:e98356

15. Berson DM. Phototransduction in ganglion-cell photoreceptors. Pflugers Arch. 2007;454:849-55.

16. Wong KY. Non-rod non-cone photoreception. In: Reference Module in Neuroscience and Biobehavioral Psychology. Amsterdam, Netherlands: Elsevier.

17. Østergaard J, Hannibal J, Fahrenkrug J. Synaptic contact between melanopsin-containing retinal ganglion cells and rod bipolar cells. Investig Ophthalmol Visual Sci. 2007:48:3812-20.

18. Saszik SM, Robson JG Frishman LJ. The scotopic threshold response of the dark-adapted electroretinogram of the mouse. J Physiol. 2002:543:899-916.

19. Marmor MF, Hodd DC, Keating D, Kondo M, Seeliger MW, Miyake Y. Guidelines for basic multifocal electroretinography (mfERG). Doc Ophthalmol. 2003;106:105-15

20. Hood DC, Bach M, Brigell M, Keating D, Kondo M, Lyons JS, et al. ISCEV standard for clinical multifocal electroretinography (mfERG) (2011 edition). Doc Ophthalmol 2012;124:1-13.

21. Robson AG, Nilsson J, Li S, Jalali S, Fukton AB, Tormene AP, et al. ISCEV guide to visual electrodiagnostic procedures. Doc Ophthalmol. 2018;136:1-26.

22. Perlman I. The Electroretinogram. Webvision. The Organization of the Retina and Visual System. Available from: http://www.webvision.med. utah.edu/book/electrophysiology/the-electroretinogram-erg.

23. Drazek M, Lew M, Lew S, Pomianowski A. Electroretinography in dogs: a review. Vet Med. 2014;59:515-26.

24. Brigell M, Bach M, Barber C, Moskowitz A, Robson J. Guidelines for calibration of stimulus and recording parameters used in clinical electrophysiology of vision. Doc Ophthalmol. 2003;107:185-93.

25. Johnson MA Jefrey BG, Messias AM, Robson AG. ISCEV Extended Protocol for the Dark-adapted Full-field ERG b- Wave Transfer (Intensity-Response) Function. Baltimore, USA: The University of Maryland.

26. Ramkumar HL, Epley KD, Tripathy K, Karth PA, Kumar UR, Shah VA Electroretinogram. Available from: http://www.eyewiki.aao.org/electroretinogram.

27. Kinoshita J, Peachy NS. Noninvasive electroretinographic procedures for the study of the mouse retina. Curr Protoc Mouse Biol. 2018:8:1-16.

28. Gjorloff KW, Andréasson S, Ehinger B. Standardized full-field electroretinography in rabbits. Doc Ophthalmol. 2004;109:163-8.

29. Hood DC Birch DJ. Beta wave of the scotopic (rod) electroretinogram as a measure of the activity of human on-bipolar cells. J Opt Soc Am A Opt Image Sci Vis. 1996;13:623-33.

30. Olivier PF, Jolicoeur B, Lafond G, Drumheller A, Brunette JR. Effects of retinal dopamine depletion on the rabbit electroretinogram. Doc Ophthalmol. 1987;66:359-71.

31. Dong CJ, Agey P, William, AH. Origins of the electroretinogram oscillatory potentials in the rabbit retina. Vis Neurosci. 2004:21:533-43.

32. Weymouth AE, Vingrys AJ. Rodent electroretinography: methods for extraction and interpretation of rod and cone responses. Prog Retin Eye Res. 2008;27:1-44.

33. Lawwill T. Practical Rabbit Electroretinography. Louisville, Kentucky: department of Ophthalmology, The University of Louisville, School of Medicine.

34. Nair G, Kim, M, Nagaoka T, Olson DE, Thulé PM, Pardue MT, et al. Effects of common anesthetics on eye movement and electroretinogram. Doc Ophthalmol. 2011;122:163-76.

35. Safatle AM, Hvenegaard AP, Otsuki D, Rodrigues E, Barros PS. Full-field Electroretinography in Healthy Rabbits According to ISCEV with Ganzfeld Stimulation. Available from: https://www.vin.com/apputil/content/defaultadv1. aspx?id=4253024\&pid=11290\&print=1.

36. Kaid T, Matsunag M, Hanaya J, Nakamura Y, Ohtani S, Miyat K, et al. Comparison between subtraction skin electrodes and corneal contact electrodes in flash electroretinograms. Nippon Ganka Gakkai Zasshi. 2013;117:5-11

37. Vinberg $F$, Kolesnikov A, Kefalov VJ. Ex vivo ERG analysis of photoreceptors using an in vivo ERG system. Vision Res. 2014;101:108-17.

38. Luebke J, Anton A, Bach M. Test-retest reliability of scotopic full-field electroretinograms in rabbits. Doc Ophthalmol. 2017:134:157-65.

39. Nao NI, Kim SY, Honda Y. The normal c-wave amplitude in rabbits. Doc Ophthalmol. 1986;63:121-30.

40. Del-Sole MJ, Nejamkin P, Cavilla V, Schaiquevich P, Moreno L. Comparison of two sedation protocols for short electroretinography in cats. J Feline Med Surg. 2018;20:172-8.

41. Liu B, McNally S, Kilpatrick JI, Jarvis SP, O'Brien CJ. Aging and ocular tissue stiffness in glaucoma. Surv Ophthalmol. 2018;63:56-74.
42. Loget O, Saint-Macary G. Determination of the effect of ketamine, thiopental and halothane on the ocular electroretinographic examination of the beagle dog to define protocols to be used in dogs, monkeys and micropigs. In: Weisse I, Hockwin O, Green K, Tripathi RC, editors. Ocular Toxicology. Boston, MA: Springer; 1995.

43. Zemel E, Loewenstein A, Lazar M, Perlman I. The effects of lidocaine and bupivacaine on the rabbit retina. Doc Ophthalmol. 1995:90:189-99.

44. Gerritsen BG. The effect of anaesthetics on the electroretinogram and the visually evoked response in the rabbit. Doc Ophthalmol. 1971;29: 289-330.

45. Schäffer EH. Pathology of the retina. Tierarztl Prax. 1992:20:510-8.

46. Kim SD, Nao-i N, Maruiwa F, Sawada A. Electrical responses from a locally detached retina and its recovery after reattachment. Ophthalmologica. 1996;210:195-9.

47. Pizzirani S. Definition, classification, and pathophysiology of canine glaucoma. Vet Clin Small Anim. 2015;45:1127-57.

48. Miller PE, Bentley E. Clinical signs and diagnosis of the canine primary glaucomas. Vet Clin Small Anim. 2015:45:1183-212.

49. Doucette LP, Rasnitsyn A, Seifi M, Walter MA. The interactions of genes, age, and the environment in glaucoma pathogenesis. Surv Ophthalmol. 2015;60:310-26.

50. Komáromy AM, Petersen-Jones SM. Genetics of canine primary glaucomas. Vet Clin Small Anim. 2015;45:1159-82.

51. Williams PA, Marsh-Armstrong N, Howell GR. Neuroinflammation in glaucoma: a new opportunity. Exp Eye Res. 2017:157:20-7.

52. Suri F, Yazdani S, Elahi E. LTBP2 knockdown and oxidative stress affect glaucoma features including TGF $\beta$ pathways, ECM gene expression, and apoptosis in trabecular meshwork cells. Gene. 2018;673:70-81.

53. Almasieh M, Wilson AM, Morquette B, Vargas JL, Di Polo A. The molecular basis of retinal ganglion cell death in glaucoma. Prog Retin Eye Res. 2012;31:152-81.

54. Munemasa Y, Kitaoka Y. Autophagy in axonal degeneration in glaucomatous optic neuropathy. Prog Retin Eye Res. 2015;47:1-18.

55. Hohberger B, Chaudhrib MA, Michalkec B, Lucio M, Nowomiejskad K, Schlötzer-Schrehardta U, et al. Levels of aqueous humor trace elements in patients with open-angle glaucoma. J Trace Elem Med Biol. 2018:45:150-5.

56. Overby DR, Clark AF. Animal models of glucocorticoid-induced glaucoma. Exp Eye Res. 2015;141:15-22.

57. Russo R, Varano GP, Adornetto A, Nucci C, Corasaniti MT, Bagetta G, et al. Retinal ganglion cell death in glaucoma: exploring the role of neuroinflammation. Eur J Pharmacol. 2016:787:134-42.

58. Arden GB, Greaves DP. The reversible alterations of the electroretinogram of the rabbit after occlusion of the retinal circulation. J Physiol 1956;133:266-74

59. Golëmez H, Yildirin M, Özer A. Is multifocal electroretinography an early predictor of glaucoma? Doc Ophthalmol. 2016;132:27-37.

60. Feiner L, Barr EE, Shui YB, Holekamp NM, Brantley MA Jr. Safety of intravitreal injection of bevacizumab in rabbit eyes. Retina. 2006;26: 882-8.

61. Pescosolido N, Barbato A, Stefanucci A, Buomprisc G. Role of electrophysiology in the early diagnosis and follow-up of diabetic retinopathy. J Diabetes Res. 2015;2015:319692.

62. Pennesi ME, Francis, PJ, Weleber RG. Photoreceptor degenerations: retinitis pigmentosa. In: Encyclopedia of the Eye. J.C. Besharse and D. Bok, eds. (Oxford: Academic Press, UK). 2010. p. 505-15.

63. Hanitzsch R. The effects of GABA and vigabatrin on horizontal cell responses to light and the effect of vigabatrin on the electroretinogram. Doc Ophthalmol. 2002;105:313-26.

64. Dong CJ. GABA feedback pathway modulates the amplitude and kinetics of ERG b-wave in a mammalian retina in vivo. Vision Res. 2002;42: 1081-7.

65. Tam WK. Effects of different degrees of cataract on the multifocal electroretinogram. Eye. 2004;18:691-6.

66. Miura G, Nakamura $Y$, Sato E, Yamamoto S. Effects of cataracts on flicker electroretinograms recorded with RETeval ${ }^{\mathrm{TM}}$ system: new mydriasis-free ERG device. BMC Ophthalmol. 2016:16:22.

67. Ratanapakorn T, Patarakittam T, Sinawat S, Sanguansak T, Bhoomibunchoo C, Kaewpanna S, et al. Effect of cataract on electroretinographic response. J Med Assoc Thai. 2010:93:1196-9.

68. Gorfinkel J, Lachapelle P, Molotchnikoff S. Maturation of the electroretinogram of the neonatal rabbit. Doc Ophthalmol. 1988;69:237-45.

69. Moskowitz A, Hansen RM, Fulton AB. ERG oscillatory potentials in infants. Doc Ophthalmol. 2005:110:265-70.

70. Milosavljevic N, Allen AE, Cehajic-Kapetanovic J, Lucas RJ. Chemogenetic activation of ipRGCs drives changes in dark-adapted (scotopic) electroretinogram. Invest Ophthalmol Vis Sci. 2016:57:6305-12.

71. Hughes S, Hankins M, Foster R, Peirson S. Melanopsin phototransduction: slowly emerging from the dark. Prog Brain Res. 2012;199:19-40.

72. Creel DJ. The Electroretinogram and Electrooculogram: clinical Applications. Webvision. The Organization of the Retina and Visual System. Available from: https://www.webvision.med.utah.edu/book/electrophysiology/the-electroretinogram-clinical-applications. 